\title{
RESÍDUOS DE INSETICIDAS CLORADOS, FOSFORADOS, ClOROFOSFORADOS, MISTURA DE CLORADOS + FOSFORADOS E CARBAMATOS EM POLPA E CASCA DE FRUTOS DE \\ ABACAXIs Ananas comosus(L.) Merril
}

\author{
Deosdedes Francisco Barcellos \\ Engenheiro-Agrônomo - Min. Agricultura \\ e Bolsista Pesq. III - B - C. N. Pq.
}

Orientador: Prof. Dr. Sinval Silveira Neto

\begin{abstract}
Dissertaçāo apresentada à Escola Superior de Agricultura "Luiz de Queiroz", da Universidade de São Paulo, para obtenção do título de Mestre em Entomologia.
\end{abstract}

PIRACICABA

Estado de São Paulo - Brasil

Junho - 1980 
Ao meu inesquecivel mano Jose Luiz

Ao Prob. Elpidio Amante.

"TN MEMORTAM"

A meus pais, meus irmäos

e Sia. Diana Condeixa "Loza"

OFEREGO. 
Aos meus dedicados MESTRES do Cusso de Pó-Graduacão em Entomo logia da ESALQ/USP, aos amigos $e$ profs. Drs. Domingos Galko, Iose de Aguiar Guimaräes e Cincinnato Rony Gonçalves, pelos sacrificios e dedicação em prol do deservolvimento da Entomologia Bilasioeira, 
Ao Prof. Dr. Domingos Gallo, DD. Chefe do Departamento de En tomologia da Escola Superior de Agricultura "Luiz de Que roz", da Universidade de são Paulo, e toda sua equipe de Docentes e Funcionārios, pelo apoio, carinho, amizade e consideração dispensados, sem os quais este trabalho ja mais poderia ter sido concretizado;

Ao Prof. Dr. Sinval Silveira Neto, meu mestre e oríentador, cuja amizade, paciência e estimulos constantes, sempre me induzlxam à fase final desta tarefa;

Ao Conselho Nacional de Desenvolvimento Cientifico e Tecno Iógico - CNPq, e ao Prof. Dr. Octavio Nakano da USP-ESAI pela bolsa concedida;

Ao Amigo e colega - Major Engo Samuel Hanthequeste Carcloso. pelos incentivos, amizade e grande colaboração;

Aos Componentes da Equipe Técnica da Seção de Resíduos do Ins tituto Biológico de são paulo, em cujos laboratörios fo ram executadas as anälises cesiduais;

Aos Prof So DrS. Paulo C. R. Cassino, José Higino R. Santes, Antonio O. Roccia e José Vargas de oliveira, pelo apojo e estimulo;

Aos Eng 8S. Agr OS. Dr S. Carlos A. Mendonça, Rubens F. Marcil lac, Luiz Edimundo R. S. Britto; Prof ${ }^{\mathrm{S}}$ Dr Sosé A. Guina rães e Dirce Pacca P. S. Britto; Dr Josẻ Camões Orlan do e Miguel A. S. Fraga, Hélì B. Nobrega, Manuel A.Roxis Rodrigues e ao Dr. Lehn Richa, Médico e Médjco Veterinärio pelos incentivos e consideração. 
Aos Eng. ${ }^{O S}$ - Agr ${ }^{O S} \mathrm{Dr}^{\mathrm{S}}$ Alda M. de Oliveira, Shinobu Sudo, Ri cardo S. S. GadeIha, Elto E. G. Gama e Joil A. Agostinni, do IPEACS- KM 47 (RJ) e da Estação Experimental de Iinha res $(E S)$;

Aos Colegas do Curso de Pós-graduação da ESALQ/USI, pelo gran de companheirismo e consideração com que sempre me dis tinguiram;

Aos Prof: Dr. Evoneo Bert Filho e Gilberto C. Batista da ESALQ/USp, pelas vaziosas opiniōes e colaboragão:

Aos Anigos Euncionärios do Departamento de Entomologia, da Seç̃o de PösmGraduação e da Biblioteca central da EsALQ/ usp. pela consideração e amizade;

A Bibliotecaria Srta. Maria Elisabeth Ferreira de Carvalho, e ao dedicado Sr. Luiz Carlos Veríssimo, da Bibioteca Central da ESALQ/USP, pela grande colaboração:

As Srta. Lizia Maria Valverde da Silva e Sra. Marly A. SiI va, pelos serviços prestados.

Aos Profs. Drs. Frederico M. Wiende e Ricardo B. Sgrillo da Seção de Radioentomologia do C.E.N.A.- C.N.E.N. e todos os amigos funcionảrios da referida seção pela maravilho sa acolhida que sempre me dedicaram. 


\section{INDICE DOS QUADROS}

QUADRO 2 -- Inseticidas utilizados, suas caracteristi cas químicas, toxicológicas, concentra ções, guantidades recomendadas por ha e aplicados por parcelas de $14 \mathrm{~m}^{2} \ldots \ldots$

- UA Ro 2 - Esquema cronológico das pulverizações pa ra os três experimentos oncle $A, B$ e $C$, referem-se ìs aplicações dos inseticidas de 14 em 14, 21 em 21 e 28 em 28 dias. respectivamente $\ldots \ldots \ldots \ldots \ldots \ldots$

QUADRO 3 - Mëdias dos resultados das anälises croma togräficas expressas em (ppm) dos inseti cidas que apresentaram residuos na polpa e casca dos frutos de abacaxis, tratados nos intervalos de 14 em 14,21 em 21 e $28 \mathrm{em} 28$ dias $\ldots \ldots \ldots \ldots \ldots \ldots \ldots$

QUADRO \& - Concentrações residuais te xicas acumula das nos Erutos dos abacaxis em 4 , 5 e 7 aplicações e concentração residual em (pom) encontrada nos intervalos de $28 \mathrm{em}$ 28,21 em 21 e 14 em 14 dias respectiva mente $\ldots \ldots \ldots \ldots \ldots \ldots \ldots \ldots \ldots$ 
NOTA TÉCNICA:

\begin{abstract}
0 PRESENTE TRABALHO REFERE-SE APENAS A "RESİDUOS DE INSETICIDAS CLORADOS EM POLPA E CASCA DE ABACAXI Ananas comosus (L, MerriL
\end{abstract} C.V. SMOOTH CAYENNE" .

TOdAVIA O TİTULO dA CAPA NÃO PODE SER MUDADO DEVIDO ĀS NORMAS VIGENTES NO CURSO DE PŌS-GRADUAÇÃO DA ESCOLA SUPERIOR DE AGRICULTURA "LUIZ DE QUEIROZ", DA UNIVERSIDADE DE SÃO . PAULO, 
O presente trabalho objetivou a anälise dos resĩauos de inseticidas na polpa e na casca dos frutos de abacazis Ana nas comosus (I.) Merril cultivar Smooth Cayenrie.

Empregou-se quatro inseticidas: BHC - 28 ; Rhodiaen drin - CE - 35\% (Endrin 25\% + Parathion metilico 10\%); Endo metil - CE - 40\% (Endosulfan 30\% + Parathion metilico 10\%); Tiodan - CE - 35\% (Endosulfai) e Testemunha (sem inseticidas) nas dosagens recomendadas pelos fabricantes.

Fez-se três experimentos com intervalos de aplica çöes de $14 \mathrm{em} 14,21 \mathrm{em} 21$ e $28 \mathrm{em} 28$ dias. Utilizou-se três blocos cada un com dez parcelas de 36 plantas e as lo plantas centrais constituiram a parcela üttl. A fxutificaço foi in duzida com Carbureto de Cälcio ( 2 g/planta) em 10/04/1972; em 26/07/2972 fez-se a primeira aplicação dos inseticidas, em $18 / 10 / 1972$ a iltima e a colheita er 05/12/1972.

Retizou-se a casca até uma profundidade de $2 \mathrm{~cm}$ e 0 resto Eoi considerado polpa. O material foi mantido em free zex até o mornento das anälises.

Empregou-se o método analitico descrito no Analitical Methods of the J.A. O.A.C. (1970) para residuos de pestici 
das clarados.

Para cada amostra de três frutos, tomou-se 509 da polpa ou casca, homogenelzou-se em "Warring Blendor" com 100 ml de acetonitrilo e $5 \mathrm{~g}$ de celite. Piltrou-se por sucçäo, completou-se o volume para $1.000 \mathrm{ml}$ e extraiu-wse o pesticida com $100 \mathrm{ml}$ de éter de petröleo; lavou-se, purificou-se, con centroumse para $1 \mathrm{ml}$ e fez-se una clarificação pela passagem em uma coluna cromatográfica contanio florisil desativado a 5\% com agua, eluiumse em mistura de étex etiilco e êtex de pe tröleo, concentrou-se e injetou-se no cromatógrafo marca Beck nam - Mod - CC - 4, contendo 10 a de DC - 200 en chronosorb -. W e velociade do papel a $0,508 \mathrm{~cm} / \mathrm{min}$.

o BrC apresentou residuos de 1.75 a 2.88 pen na cas ca e 0.05 a 0,07 ppm na polpa: Enarin (Rhodiaendrin) na ces ca, 0,08 ppm e na polpa traços (ppt): Endosulfan (Endometil). apenas na casca, 0,09 a 0.11 ppm e na polpa, tambem encontra -se (ppt): Endosulfan (Thiocan), apenas na casca se fez pre sente com 0,09 a 0,38 ppm. Na polpa, Igualmente detector-se (ppt). 
$2-I N T R O D U C A O A$

O abacaxi è uma planta da familia Bromeliaceae e gê nero Ananas compreende diversas espécies, cultivares e va riedades。

A espécie mais cultivada no mundo è a Ananas como sus (I.) Mercil cultivar smooth cayenne. A planta é originâ ria do Continente Americano e se distribuiu desde o sul do Estado da Florida (USA) até o Norte da Argentina. Pesquisas fitogeográficas revelaram que o Erasil central é a região de origem desta Bromélia e de lá foi distribuída para as demais regiões do globo.

Com bases na necessidade nacional de incrementax as exportaçoes, reduzir os gastos com as aplicações onerosas de inseticidas e minimizar os cesíduos destes pesticidas nos frutos e no mejo ambiente; o presente trabalho foi realizado.

Alërn disso, os resíuos de inseticidas se constituem em fator limitante para os importadores dos produtos abacari colas tais como sucos, conservas em exal atë mesmo os Exu tos "in natura".

A cultivar Smooth cayenne é a de maior plantio no mundo e, atualmente seu cultivo vem se expandindo muito no Brasil. A introdução dessa cultivar em territorio brasilej. 
ro se deu em 1930 e foram feitos os primeiros plantios em Mr nicipio de Registro, no litoral pauista e logo após difun diu-se por todo o Estado e por algumas regiões do pais onde outras cultivares exam plantadas.

Uma pesquisa mercacológica visando incrementar as ex portações dos nossos produtos abacaxicolas realizada pelo MINISTERIO DO INTERIOR (1976) através do Banco ào Nordeste do Brasil e Secretaria da Agricultura de São Paulo, na Euro pa e Estados Unidos ; por outro lado O BANCO DO BRASIL (1975) através de sua Carteira de Comércio Exterior (CACEX) indica os Estados da Paraiba, São Paulo, Espirito Santo e Rio de Ja neiro, como potenciais proautores e exportadoxes do Eruto " in natura" e Industrialızados não só pelo volume de produção como pelas propriedades organoléticas dos frutos dessas re giőes.

os principais países compradores são Argentina, Itä Iia, Reino Unido, Canadä e Estados Unidos, sendo que o consu mo tem aumentado abruptamente no Oriense Médio.

Em seu PROGNOSTICO (1975) a Secretaria da Agricui tura do Estado de são paulo prevê safras capazes de dar aten dimento a todos os pedidos de importadores até 1980 e o BAN CO DO NORDESTE DO BRASIL (1976) afirma que o abacaxi nordesti no tem conseguido penetrar em todos os mercados mundiais on de é oferecido e tem uma excelente aceitação; mesmo a cult var "Pérola ou Branco de Pernambuco" que apresentam. baixa acidez tem mercado certo na Alemanha e Reino unido gue dão preferência ao caynne por sex àcido.

GIACOMELII (1977, 1977a e 1978) explana os resulta dos de suas viagens ao mundo abacaxicola mencionando que o Brasil possui as maiores perspectivas para assumir uma pols tica de exportação de abacaxis em todas as suas formas, en tretanto ë extremamente necessârio que se leve a sêrío os problemas fitossanitärios que dizimam nossa abacaxicultura. 
SIMÃo (1971) relata que o abacaxizeiro possui uma constituição especial nas células epidérmicas que revestem a superficie foliar e pode armazenar ăgua por longos períodos e consequentemente, se adaptar a regiões nas quais os indices pluviométricos näo conseguem suprir as exigências de nenhuma outra cultura; os solos arenosos são os que oferecem o me Ihor desenvolvimento para as plantas.

Os frutos dos abacaxis brasileiros apresentam exce lentes qualidades organoléticas e sua cor, sabor e consistên cia são os principais responsäveis pela ótima aceitcação no mercado internacional, não só para o consumo "in natura" co industrializado. 
GIACOMLLL (1973) menctona que emora o brasil se ja um des maiores produtores mundiais de abacaxi, vem utilizan do técnicas agronômicas bem rudimentares ; em consequência advem o bajxo rendimento, frutos pequenos e de formas irregular alëm de apresentar um dos maiores problemas fitossanitários mundiais, mesmo assim, o Brasil se mantém como o segundo pro dutor mundial de abacaxi.

Dentre as muitas variedades existentes, apenas três mantẻn a prodmazia do cultivo devido ao seu valor comercial, são elas: Branco de Pernambuco ou Pérola, Amarelo de Boituva e Smooth cayenne.

$$
\text { PY \& TISSEAU (1965) jä revelaram que as indüstrias }
$$

de conservas de abacaxis ocupam o segundo lugar no mundo Eican do a primeira colocação para as dos pêssegos.

\section{2 - DEFINIGOES E CONCEITOS}

Um breve histörico dos pesticidas feito por ROBERTS (1971), relata que a 900 anos A.C. os chineses jä utilizavam - Arsênico para controlar insetos que atacavam jardins.

Antes de 1.300 Marco Polo empregou oleo mineral con tra moscas que atacavam cemelos.

Em 1746 Collison, na Inglaterra recomendado por BeI tlan, usou infusão de folhas de tabaco que este usava com su cesso na Amêrica para controlar insetos-pragas inclusive cur culionideos, antes de 1763 na wranģa, afíaios eram tambëm 
controlados com o uso do tabeco.

De 2800 a 1900 o nümero de produtos minerais e vege tais foram desenvolvidos com o objetivo de controlar insetos mas, foi de 1900 a 1935 que os maiores avanços foram assinala dos e depois de 1940 os compostos de hidrocarbonetos clorados e os organofosforados acabaram por trazer as grandes inovą̧ões. clorofosforados, carbamatos e outros inseticidas modernos EO ram logo sintetizados e assumindo posições de destaque ; junta merte com todo estes avanços tambëm surgiram com grande rapi dez, os graves problemas da poluição alimentar e ambiental.

Descrevendo os procedimentos básicos utilizados pe los seus Grupos de Trabalhos sobre o controle oficial dos pra guicidas a EAO (1971) expõe uma terminologia, nomes técnicos, armazenamento, tomadas de amostras e aspectos gerais sobre anâa Iises quimicas dos praguiciaas.

ALMEIDA E PEREIRA (1973) dizem que, o termo saúde ‥ cupacional na agricultura é um conceito moderno e adveio do grande numero de casos relacionados com o uso inadequado dos pesticidas e tem por objetivo analisar os problemas de saúde püblica, problemas específicos, riscos ocupacionais, dados es tatisticos sobre acidentes ocupacionais na Agricultura e tam bẻm uma Organização dos Serviços de Medicina Agrîcola por su gestão do Organização Internacional do Trabalho e da organiza ção Mundial de Saúde.

Há mujto, as pesquisas sobre resíduos de pesticidas vem sendo uma das maiores preocupações em todo mundo. No Bra 


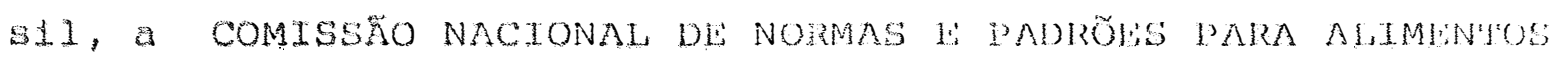
(1974) om sua Resolução no 12 dá algumas definições essenciais para uma melhor compreensão dos trabalhos envolvendo re rivos:

3. - Pesticidas:

E a substância ou nistura de substâncias destinada a prevenir a ação ou destruir direta ou indiretanente inse tos, ācaros, roedores, fungos, nematóides, ervas a aninhas, bactérias e outras formas de vida animal ou vegetal prejudiciais à lavoura, à pecuária, seus produtos e outras matérias primas alimentares.

2 - Residuo de pesticida:

A quantidade de pesticidas e/ou seus derivados re manescentes no alimento, em decorrência do emprego de pesticida e expresso em partes (em peso) do pesticida e/ou seus ce rivados pox un milhão de partes (em peso) do alimento (ppm).

3 - Residuos desprezivel:

Quantidade de resíduo de pesticidas considerada to xicologicamente insignificante.

4 - Resiuuo não intencional (Iimite prätico)

o que ocorre no alimento como resultado da contami nação sem que o pesticida tenta sido aplicado intencionalmen te. 
5 - Dose diária aceitável:

Quantidade máxima que, ingorida durante toda a vida, parece não oferecer risco apreciävel à saúde, à luz dos conhe cimentos atuais. E expressa ern mg do pesticida por $\mathrm{Kg}$ de peso corpóreo $(\mathrm{mg} / \mathrm{kg})$.

6 - Tolerância:

E definida como sendo a quantidade de residuo de pes. ticida tolerada no alimento, como decorrência de sua aplica çäo adegueda, auma fase especifica desde a sua produçäo atè o consumo: expressa em partes (em peso) do pesticidas e/ou seus ceriavoos, por um milhão de partes (em peso) do aijmento (ppm).

7 - Limite de resíduo não intencional (Limite de resíduo prăti co).

Quantidade máxima de resíduo näo intencional de pes ticidas tolexada em alimentos, expressa em partes (em peso) do pesticiaa por un milnão de partes (em peso) do alimento (ppm).

8 - Intervalo de segurança ou período de carência:

E o intervalo de tempo entxe a última aplicaçăo do pesticida e a colheita ou comercialização do vegetal, abate ou ordenha do animal, se for o caso, a fim de que os residuos es tejam de acordo com as tolerâncias.

9 - Uso adequado ou boa prātica agrícola:

Q emprego correto e eficaz de um pesticida, consi 
derado os riscos toxicolögicos envolvidos em sua aplicacão, de modo que os residuos sejam os menores possiveis e toxicologica mente aceitáveis.

10 - Amostra subjetiva:

Amostra representativa colhida apôs o emprego conhe-cido ou suspeitado de um pesticida.

1. Amostra objetiva:

Amostra representativa colhtal sem conhecimento prëm vio de uso do pesticida.

Esse documento estabelece atnda os critêrios para os Iimites residuais e as respectivas tolerâncias dos pesticidas, e/ou seus derivados em alimentos industrializados ou "in natu ra" , matérias primas alimentares e produtos alimentioios; as sunto que jả havia sido objeto dessa mesma Comissão, quando tratou dOS RESTDUOS DE PESTICIDAS EM ALIMENTOS (2972).

Os alarmes de CARSON (1962) nos Estados Unidos e os noticiärios como os do JORNAL DO B更ASIL (1973) despertaram uma grande tomada de consciência da gravidade dos problemas dos residuos nos erutos e hortaliças do Rio de Janeiro, São paulo e outras grandes capitais brasileiras.

Os Orgãos Ministeriais e em especial os Institutos Biológicos e Instituto Adolfo tutz, em são paulo, não têm medi do esforços dentro de suas possibilidades visando minimizar os riscos ocupacionais e os restauos cos inseticidas nos alimen 
tos. Un SIMPósto realizado en (1973) relata os resultados sobxe residuos de pesticidas em alimentos com algumas recomendações es senciais:

a - Recomendarões do uso seguro e eficiente dos pesticidas de vem sex amplamente divulgadas por todos os meios possiveis. visando reduzix os riscos de poluição alimentar:

b - Efetuax controle rotineiro das hortaliças, frutos e outros procutos agricolas; e

- Apllcar a Ieglslagão existente e realizar cursos visando o uso correto e adequado dos pesticidas na Agropecuéxia e ou tras providências que visem reduzir ao minimo os residuos nos alimentos industrializados e "in natura"。

O MINISTERIO DA AGRTCULTURA (1978, 1978a) divuldou um Catäłodo atualizado dos Defensivos Agrícolas e tambëm uma valio sa publicação sobre "Prevenção de Acidentes no Uso ảos Defensivos". Essa publicação, alēm de inümeras informações üteis sobre os de fensivos, relacionou todas as Portarias Ministeriais, Decretos e Resoluções Federais sobre os befenstvos Agropecuärios em uma pu plicação sobre prevenção de Acidentes, deu uma relação dos defen sivos registrados na Divisäo de Defesa Sanitáría vegetal e ofereceu dados gerais sobre seus effeitos toxicológicos, DI, 50 "modos de evitar os envenenamentos e terapia das intoxicações. 
$3.3-$ OS PESWICTDAS EM SAOD: POBLICA

OLSEM (1971) comentando sobre os pesticidas em saǘa püblica disse que, uma vez lançada no mercado todos säo üteis e muitos deles, indispensäveis à sobrevivência do homem mo dexno mas, estão sendo díspensados poucos cuidados no que tan ge ao seu uso. o mal emprego destes dexivados ouimicos está levando o homem moderno a uma catástrofe incalculävel com a po Iuição do ambiente, dos alimentos e de seu pröprio organismo.

GRAHAN (1971) Ealou sobre os efeitos beneficos dos inseticidas destacando que a exradicą̧a da maläria nos testa dos unidos aurarte a Segunda Guerra Mundial e tambëm a erradi cạão e controle de diversos vetores como os dos insetos Aede e Cuzex transmissor da wulehereria bancrofti causador da le lefantiase) , são exemplos da grandesa d uso dos pesticidas, mas, ë bom que não nos esqueçamos dos seus nocivos efejtos so bre o agromecossistoma.

TUCKER (1971) relatou que os carbamatos e os fosfora dos podem substituir os clorados porëm os problemas dos resi duos não ficam resolvidos, pois outros eventos como intoxicações agudas e efeitos carcinogênicos vên a ocorrer.

ALMEIDA (1974) mencionou vários tópicos como núveis de inseticidas organo-clorados no teckdo adiposo humano, no sangue, influência sobre o sistema enzimático dos mamiferos, tumorigêne se em animais de laboratörio, as relações do DDT com neoplasias 
no homem, mutagênese, significado epidemiológico dos nĩveis de inseticidas organoclorados nas populações e atẻ da utilização do DDT e DDD para fins terapêuticos onde THOMPSON et alii (1969) que administrando DDT por via oral a um jovem que apresentava icterícia não hemolítica familiar não conjugada, e os resulta dos foram plenamente favoráveis, persistindo por sete meses a pōs a administração do DDT. Não foram observados efeitos co laterais ou secundários, não houve proteinúria e todas as pro vas hematológicas e de funções hepáticas foram normais.

Anteriomente o referido paciente havia sido trata do com fenobarbttona por alguns meses, entretanto, com a sus pensão da medicação subiu de novo o nĩvel de bilirubina no san gुue.

3.4 - DEPOSICÃO, PENETRAGAO E PERSISTENCIA

HUNT (1966) explica que uma das causas do aumento da produção mundial de alimentos foi o aparecimento dos insetici das clorados durante a Segunda Guerra Mundial e, apesar de sua grande estabilidade e persistência poucos foram os estudos rela cionados com o uso indiscriminado desses pesticidas. Quando em solos cultiväveis existem níveis altos de organoclorados, po de ocorrer fitotoxicidade. Em análises residuais, pequenas quantidades foram detectadas em plantas, animais e no leite de 
vacas e cabras. Ao analisar äguas de riachos que sofrcram tra tamentos contra simulideos, culicideos e outros insetos de inte resse em Campanhas de Saüde Püblica, constatou-se grande morta lidade de peixes e outros animais aquáticos, bem como grandes quantidades de resíduos foram encontrados nas anälises.

PALMBLAD (1971) relatou que são raras as comunidades que já não estejam expostas aos pesticilas e seus efeitos malé ficos; mesmo nas regiōes muito frias onde as pragas são bem me nos intensas os seus habitantes se contaminam com os alimentos produzidos em outras partes; alëm disso, os pesticidas nessas regiões conservam seus efeitos toxicolögicos por ternpo mais pro Iongado devido ao menor efeito da temperatura e de outras intem përeis na velocidade das reações químicas e conseguente redução do metabolismo e da cinêtica das reações dos mesmos.

$$
\text { A FAO-OMS (1970a, 1970b, } 1976 \text { e 1977), revela a na }
$$

tureza e origem da resistência das pragas aos inseticidá, in formando que o advento dos mordenos inseticidas com sua eficâ cia e Eacilidade de utilização levaram os agricultores, a torna rem abusivos os seus usos. Estes fatores contribuiram sobrema neira para o surgimento de espëcies de pragas fisiologicamente resistentes a uma grande parte dos inseticidas utilizados. $\tilde{A}$ medida que se incrementa a utilização de certos pesticidas, no vas espëcies de pragas saõ relatadas como não respondendo mais aos efeitos toxicológicos dos inseticidas, até se constatar que - produto näo funciona mais para o fim a que se destina, passando a se constituir em um perigo para a poluição alimentar e am 
biental. A substitulcão ou mistura dos inseticiar po dem ser medidas paleativas e temporárias já que a resistência ê sempre um fenômeno genëtjco previsto.

BARON (1971) comentou que em nações subdesenvolvidas há um esforco muito concentrado dos agricultores para in troduzir pesticidas em seus planos culturais objetivando um acréscimo de produtividade mas, os técnicos que os aconselham essas medidas não lhes mostram os cälculos econônicos racio nais, nem os reais perigos residuais e ocupacionais. Os ca sos de insucessos dos inseticidas não são raros; igualmente, muitos problemas de intoxicações ocoxrem devido ao manuseio inadequado, com isso, há uma discrença quanto à real função cos defensivos.

Por outro lado AIMEIDA (1973) menciona 94 Nações en tre as guajs o Brasil fazendo parte da Comissão do Codex Ali mentarius através de sua Comissão para Residuos de pesticidas. Esta Comissão se reune anualmente e, seus membros são repre sentantes das Nações unidas. Nessas reuniões são discutidos se os residuos de pesticidas remanescentes nos alimentos não ultrapassam a dose diária aceitável recomendada e são apresen tadas sugestöes sobre os residuos de pesticidas em alimentos e seus efeitos colaterais no organismo humano.

Um esquema mostrando o fluxo grama dos destinos dos pesticidas foi confeccionado por EDWARDS (1970) revelando o ciclo dos pesticidas no ar, solo e ägua com algumas correlações existentes nas plantas. 
MECTALF e FLINT (1972) explicam que os residuos dos inseticidas orgânicos penetram rapidamente e acumulam-se nos tecidos gordurosos das plantas e animais. A parte que fica na superfície é logo degradada peio intemperismo e, a parte penetrante está continuamente exposta aos enzimas e ácidos das plantas e/ou animais. O efeito da degradação é expresso mais convenientemente como una curva residuo persistente e que se gue a cinética de primeira ordem e é uma função linear quando representado graficamente como sendo o $10 \mathrm{~g}$ da quantidade de resíduos dividzo pelo tempo.

FENH e BERTELS (1971) enunciaram värios ensaios cu jos resultados foram utilizados para cálculos da dose diăria aceitável e dose letal para cobaias e sua extrapolação para ○ homem .

$$
\text { O'BRIEN (1967); MARTIN (1968) : KENAGA e ALIISON ( }
$$

1969) : GIANNOTTI et alii (1972); KENAGA e END (1974); BATISTA (1974); NAKANO et alii (1977) e GALLO et alii (1978) fizeram amplas considerações sobre os värios inseticidas em pregados neste trabalho e abordaram aspectos de suas composiÇões, toxiciaades, fórmulas químicas, percentagens de princ pios ativos, locais, anos e autores de suas descobertas. AI guns dos autores supra se aprofundaram em certos captulos de suma importância como a degradação dos pesticidas no solo e organismos vivos, metabolismo em mamíferos e plantas, sintoma tologia e tratamento das intoxicações.

GUYER (1969) apresentou considerações sobre alguns 
casos de intoxicações por uso inadequados e abusivos de certos pesticidas e recomenda programações aproprizdas com ênfase pa ra os perigos causados pela poluição, efeitos na saüde pübli ca e possüvełs falhas nas aplicações das sanções legais.

STREET (1971) recomendou que todos os pesticidas foS sem rigorosamente controlados sob os seus diversos aspectos e que previdências enêrgicas devem ser tomadas no que concerne a Iançamentos de produtos que näo obedeçam rigorosamente todas as normas mundiais de tolerâncias residuais em alimentos e toxico lögicas.

PIEDADE (1975) cita que, para os casos dos defensi vos como Endrin e Parathien metrico que são extremamente ins tavela, as formulações devem ser adicionadas com 1 a $5 \%$ de es tabilizantes. Se a formulaço passar peio teste de armazena mento, pode ser considerado estável.

NEUHOLD (1971) frizou que apesar dos esforços em pesquisar-se o complexo dos residuos em alimentos, ainda é in significante o nünero de dados e informações concretas que aju de a eliminar os perigos dos residuos em frutos e outros mate xiais alimentares.

GIAINOTIT (1973) Ealando sobre os residuos de inse ticidas em produtos agrícolas diz que entre os fosforados e os carbamatos existem värias opções para se evitax os residuos nos vegetals; a melhor delas é procurar selecionar produtos cu ja via mëda do restauo seja da ordem de um a trés dias. A programaçăo conveniente e acieguada do controle das pragas è tambërn um fator de máxima importância. 
FORMAN et alii(1965) jä frisava que o Endosulfan é formado por dois isômeros que diferem em suas propriedades fisicas, quimicas e toxicológicas ; informando que o produto de degradação do endosulfan em organismos animais e super ficies de plantas é a forma sulfato que, ao conträrio do pro duto original não possui os isômeros I e II, cujas fómulas espaciais são apresentadas a seguir:

\section{A - (alfa) endosulfan ou isômero I}

B - (beta) endosulfan ou isômero II

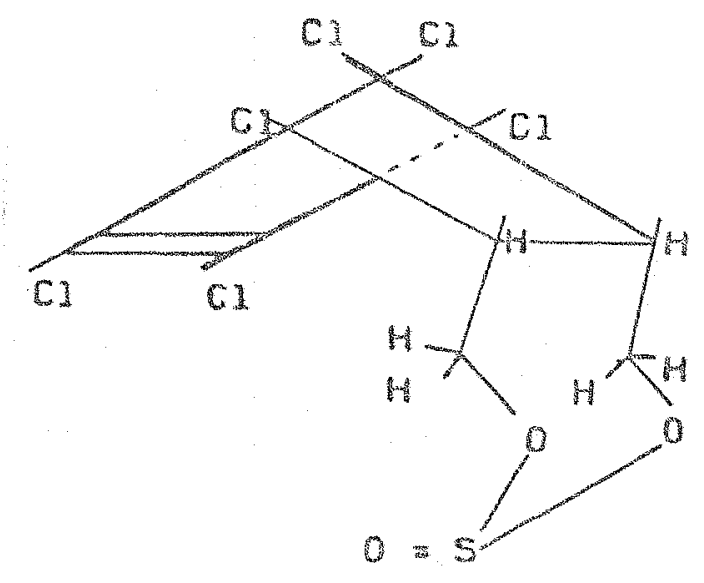

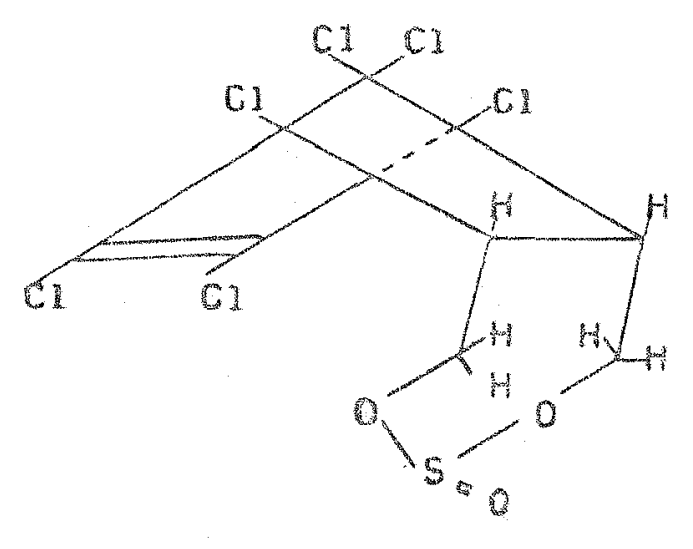


MAIER BODE (1968) apresentou a fórmula plana do endosulfan e disse que esse pesticlda é usualmente classifica do como um inseticida clorado do grupo dos ciclodienos mas, ele è tão diferente dos demais inseticidas desse grupo (como o aldrin, endrim, dieldrin, etc.) em suas propriedades quimi cas, efeitos fisiolögicos e comportamento nos oxganismos ani mais e superficies de plantas que o autor acha que esse inse tícída não deveria ser colocado nesse grupo.

os primeiros relatos da constatação de grandes ní vels restduals dos pesticidas em solos apareceram nas décadas de 50 e 60 e foram assinalados por FLEMING e MAINES (1953); GINSBURG e REED (1954) e LICHTENSTEIN (1958), enquanto peque nas quantidades eram constatadas em äquas e fundos de riachos POI ROSEN E MIDDLETON (1959).

Os trabalhos de DE WITT (1955), HuNT (1966) e ED WARDS (1970) mostraram que os tecidos adiposos de verterbrados e invertebrados não eram as unicas reservas residuais dos clo xacos mas, as camadas superiores da cadeia alimentax também são repositôríos desses pesticidas.

No que se refere à absorção dos insetjcidas e seu mecanismo de toxicidade SHARMA (1971) esquematizou os cami nhos percorridos pelos radicais ativos e os bloqueios causados. Disse que todas as manifestações de sintomas de envenenamento decorrem sempre das manipulaçöes inadequadas e da falta de a plicação de um mínimo de conhecimento sobre os pesticicas. Não são raras as ocorrências de casos fatais que certanerte pode 
riam ser evitados se alguns cuidados e conhecimentos fossem ob servados.

LINDGREN e VICENT (1968) comentaram residuos de inse ticidas em produtos fruticolas e referiram-se ao abacaxi menci onando que foram aplicados e pesquisados clorados, fosforados e o carbaryl, mas não detectaram residuos deste inseticida.

A propósito dos agentes contaminantes dos frutos e conservas de abacaxi a FAO-OMS (1970) menciona os inseticidas como os agentes mais comuns e mais perigosos, entretanto, à se melhança de que ocorre nos diversos trabalhos, não são citados os limtees de tolerâncias para o abacaxi e seus subprodutos. Em un des mais completos trabalhos sobre residuos de pesticias a Frow WHO (1971.c) apresentou um sumärio das reco mendações concernentes a dose duăria aceitável, tolexância li mites präticos de residuos permitidos nos alimentos em geral。 todavia o abacaxi não consta da lista dos frutos pesquisados. PIGATII (1973) reporta-se aos mëtodos biolögicos co mo bem valiosos para a pesquisa de resỉduos em diferentes ma teriais e que apesar de suas limitaçẽes, podem ser usados com sucesso na investigậão da presença de tóxicos como um método preliminar de triagem de amostra em laboratório que necessitam levar a cabo um grande nümero de anälises como trabalho de ro tina. A partir dessa triagem inicial, outros métodos podem ser recomendados para a obtenção de maior precisão nas deter minaçōes resijuaj.

RUEGG (1975) utilizando técnicas de radioisötopos pa 
ra estudar os efeitos residuats de pesticidas em plantas ali menticias concluiu gue a técnica da autoradiografia permite determinar qualitativa e semi-quantitativamente a presença de pesticldas marcados e aplicados às plantas. Os sistêmicos são absorvidos e translocados pela seiva nos tecidos vegetais e, desse modo, en qualquer fase podexá ser detectado pelas técnicas da radiojsotopia. O vegetal marcado emite radiaçoses que imprecionam un filme de raio-s. Se a distribuigäo for homogênea ou se eja for concentrada mais em certas partes das plantas como os frutos, isto e particularmente util poss. para o caso dos Erutos que são consumidos "in natura" como o abacaxi. somente após uma determinada fase de degradação do pestıcida, é que o fruto poderä sex distribuido para o consumo.

$$
\text { FAOWHO (1967, 1968, 1969, 1971, 1971a e 1971b) }
$$

enumerou os culdados gue devem ser tomados com os residuos de pesticidas nos alimentos e relaciona uma grande variedade de inseticidas e seus limites de residuos permitidos em alimentos mas para os frutos de abacaxi e seus derivados nada $\vec{e}$ comen tado.

De acordo com ALMFIDA e SVBrLICIC (1972), no Bra sil as aplicaços de pesticides na agricultura, muito têm con tribuido para a contaminação ambiental, de frutas e hortaliças de uma maneira geral.

GAETA (1974) pesquisando os riscos e controle de in dividuos expostos a ação dos pesticidas refere-se aos inseti 
cldas organo-fosforados como os implicados no maior nümero de Intoxicações humanas e que o parathion etrlico é o inseticida mais conlecido como causador de envenenamentos acidentais, ㅇ cupacionais e epidêmicos e a consequente manifestação sinto matológtaca pode confundir-se com algumas situações de emergên cias tals como: enfarte do miocärdio, encefalites e edemas pulmonares; em cxianças os sintomas se confundem com crises as máticas, epileppticas e de preumonias agudas.

OLIVETRA e BATISTA (1976) empregaram o método da Bio-anảise con larvas de Aedes aegypti para a avaliação quen titativa de residuos de inseticidas organofosforados em couve e chegaram a bons resultados. Através do estabelecimento da curva de degradaçäo, determinaram um pexiodo de carêncta de trës dias para o malation e sete dias para o paratiom metil com Imites de tolexäncia de 8 ppm e 1 ppm respectivamente.

3.5 - A CROMATOGRAFIA A GAS EM ANALISES DE RESTDUOS

Existem controvërsias no que se refere ao primeiro pesquisador a empregar o detector de capturas de elétrons para anêzises de inseticidas clorados.

De acordo com Gudzinowicz (1967) e MC Nair e Brone 11i (1969), citados por RIBAS (1976) e cromatografia fol usada pela primeira vez em 1905 por $W$. Ramsey.

Em 1906 M. Tswett obteve faixas coloridas quando pas sou extratos de plantas atraves de uma coluna cromatogrä́fica e 
foi o primeiro a usar o termo cromatorrafia; apesar de CIOLA (1969) discordar da propriedade do termo já que materiais in colores e também gases são separados por esse processo.

A cromatografia a gás è definida por GUdzinowICz (1967) ; SCHUPP III (1968); CIOLA (1969); MC NAIR E BONEL II (1969) ; TRANCHANT (1969) e BREITNER (1972) como um mëtodo físico de sepração no qual os componentes a serem separados distribuidos entre duas fases onde uma delas é estacionáría e de grande superfície e a outua é un flutio que percola atra vés da primeira. Reforçando esses conceitos, RIBAS (1976)diz que a cromatografia è uma técnica usada para separar substâncía voläves pela percolação de uma corrente de gãs atravēs da fase estacionäria supertada por uma coluna de vidro, metal ou teflon mantida ou não sob aquecimento e prossegue o autor mencionando que no caso de a fase estacionária ser um sólido temos a cromatografia gás-sólido e os sólidos comumentes uri 13zados nesse típo de cromatografia são sillica gel, peneira mo lecular ou carvão, todos de alta superfície.

Se a fase estacionäria for um líquido, tem-se a cro matografia gās-líquido onde um líquido pouco volātil e distri buido em uma pelicula muito fina sobre um sólido poroso e i nérte que é chamado de suporte sólido. Exemplos de sỏlidos inertes mais comumente usados em cromatografia gās-líquido pa ra anälise de resíduos são Chromosorb, Gäs Chrom Q. Anakron. e outros. Dentre os inertes majs utiljzados na rase Ijquj da cita-se DC-200, Apiezon, QF - 1, Carbowar, SE - 30, DEGS 
$.0 V-17$, etc.

Para se analisar, residuos de pesticidas emcromatograria gás-IIquido é a mais usada; os detectores mais emprega dos são os de captura de elétrons, fotometria de chama, chama alcalina e micxomcoulomëtrico.

ETTRE e MC FADDEN (1969) dizem que o nümero de cro matögrafos atualmente em uso em todo mundo supera o de todos os instrumentos de quaisquer outros métodos analiticos.

JAMES e MARTIN (1952) estudando diferentes combina çōes de fases möveis e estacionärias conseguiram descobrir a cromatografia gäs-liquido a qual, pela sua sensibilidade, ve locidade, precisão e simplicidade na separação e outras exce Ientes caracteristicas präticas, teve um crescimento muito rápido.

JOHNS $e$ BRAITHWAITE (1964) citam Adlard e whithan como os primeiros a usarem a cromatografía a gäs em análises de mistura de pesticidas os quais observaram também que a sen sibilidade do detectos de condutividade térmica por eles usa da era bem limitada para o seu emprego em análises de resíduos. FRHRESE (1964) pesquisando os fatores correlatos com as anälises de pesticidas em alimentos, concluiu ser a croma tografia o mëtodo que melhor se coaduna por permitir, ao mes mo tempo separar e identificar quaisquer residuos presentes. LARA (1971) considerou todos os modernos conceitos sobre pesticidas e seus residuos em alimentos e relatou a me todologia empregada no Instituto Adolfo Litz, em Sã paulo, para a determinação dos residuos dos inseticidas clorados em 
alimentos vegetais e animais; na maioria dos casos a cromato grafia a gás é o método mais empregado. 
4- MATERIAL E MËTODOS

4. I - INSTALACAO DO EXPERINENTO

Foram realizados três experimentos na mesma êpoca, objetivando análises de residuos dos inseticidas clorados na polpa e na casca dos frutos de abacaxis - Ananas como sus (I.) Mexril cultivar Smooth Caynne. Os experimentos obedeceram a três intervalos de aplicações dos inseticidas a saber: de 14 em 14,21 em 21 e de 28 em 28 dias respec tivamente.

Utilizou-se o delineamento ""Experimentos inteiramente casualizados" contando cada um com três blocos e ca da bloco com dez parcelas de 36 plantas. As dez plantas centrais foram consideradas plantas úteis da parcela ou 
parcela ütil, das quais foram coletados os frutos para as anälises restauais.

Utilizou-se 4 (quatro) inseticidas enunciados com as letras de $A$ até $D$ sendo que a letra $T$ designou a testemunha, (parcela sem nenhum tratamento) e foi pulverizado apenas com ågua.

os inseticidas empregados foram:

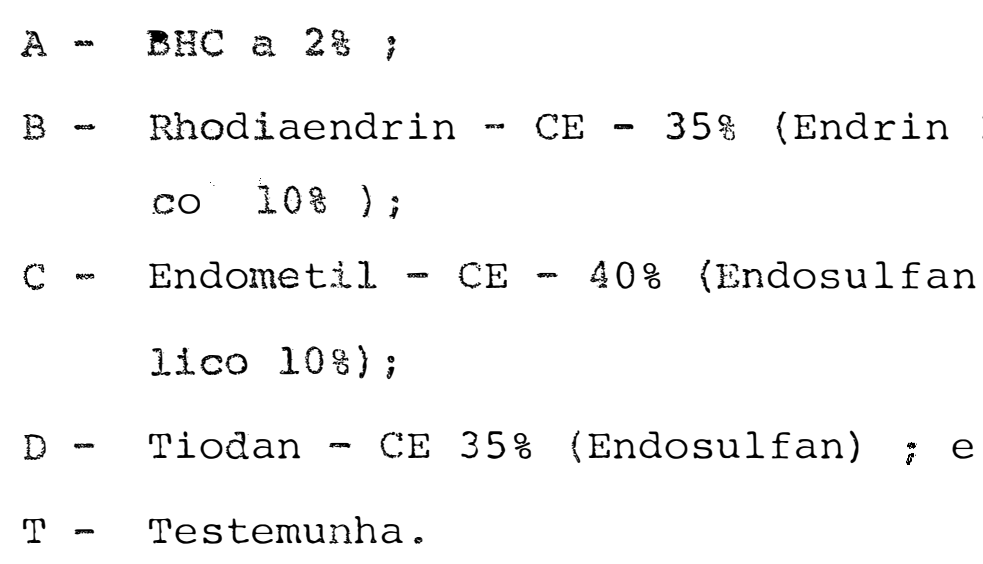

os suadros 1 a 4 , relatam as designaçöes tēcnicas, nome quimico, quantidades dos inseticiaas das formulações co merciais e dos principios ativos por hectare e por parcela de $1 . \mathrm{m}^{2}$.

Todas as plantas do experimento foram provenientes de mudas do tipo rebentão e tiveram sua frutificação induzi da pela aplicação de carbureto de cálcio à razão de 2 g/plan ta. A carburetação foi feita em 10/04/1972. Em 14/06/1972, (65 dias apōs a aplicação do carbureto), observou-se que 95\% das plantas haviam emitido a "roseta floral" . No dia 26/07/ 1972 efetuou-se a primeira aplicação dos inseticidas, cujos detalhes estão relatados nos quadros 1,2 e 4 . 
Na data da primeira aplicação coletou-se um fruto de cada parcela, pesou-se e reticou-se a média geral, a qual foi estimada por aproximação em $200 \mathrm{~g}$. O mesmo procedimento foi executado nas aplicações subsequentes.

A [ultima aplicação dos inseticidas nos três experi mentos foi no dia 18/10/1972 (Quadro 2). Em 05/12/1972,47 dias após a ültima aplicação foi feita a colheita dos expe rimentos.

- 2 - PROCESSAMENTO DAS AMOSTRAS

As amostras para as anälises dos resíduos se consti tuiram de frutos congelados desde o momento da colheita até os procedimentos de laboratörio para as determinações das quantidades dos resỉduos persistentes.

Foram tomados seis frutos de cada parcela, retirou - se a casca até uma profundidade de 1,5 a $2,0 \mathrm{~cm}$ e o restan te foi considerado a polpa.

Para cortar os frutos utilizou-se facas que teve suas Jâminas lavadas com ảgua e sabão duas vezes após cada corte. Os abacaxis foram cortados sobre papel aluminizado os quais foram descartados apös cada uso. A polpa ou a casca foram a condicionados em papel aluminizado e depois colocados em dois sacos plásticos de modo a garantir o mais perfeito isolamento das amostras. Após estes procedimentos cada amostra, indivi dualmente, foi colocada em um vidro de boca larga e " estes 
foram levados a un congelador. Em segulda, acondicionou-se as amostras em caixas bem fechadas em formato de cubas, colocou-se picado e transportou-se à noite, desde a sede do Instituto de Pesquisas Agropecuārias do Centro-Sul (IPEACS), no Krm 47 da An tiga Rodovia Rio-São Paulo, em Itaguai, RJ., até a Seção de Re síduos do Instituto Biológico de são Paulo.

Desde a chegada a Seção de Resĩduos do Instituto Bio lógico, todo material foi armazenado em Freezer até o instante do processamento das amostras para as anālises cromatogräficas.

4.3 - METO EMPREGADO PARA AS ANALISES

O método empregado para as determinações dos residuos dos pesticidas foi o descrito para analises dos pesticidas clo rados que se encontra no Analitical Methods of the J.A.O.A.C. (1970) com modificações e adaptações feitas pela Equipe Técnica da Seção de Resỉduos de Pesticidas do Instituto Biológico do Es tado de são Paulo.

As partes dos frutos (polpa ou casca) foram homocenei zadas por moagem em "Waring Blendor" ou equivalente agitancio-se em alta velocidade.

Tomou-se $50 \mathrm{~g}$ do material homogeneizado, adicionou-se $100 \mathrm{ml}$ de acetonitrilo e $5 \mathrm{~g}$ de celite 545. Novamente, o mate rial $(50 \mathrm{~g}$ da amostra $+100 \mathrm{ml}$ de acetonitrilo $+5 \mathrm{~g}$ de celite 545) foi misturado por agitação em alta velocidade em "Waring 
Blendor".

Filtrou-se por suç̧ão e transferiu-se o filtrado para uma Proveta graduada de $100 \mathrm{ml}$ e completou-se o volume com ace tonitrilo.

Tomou-se em um funil de separaçẫo de $1.000 \mathrm{ml}$, diluiu - se con ägua e extraiu-se o pesticida com $100 \mathrm{ml}$ de ëter de pe tröleo.

A purificação dos pesticidas foi feita inicialmente no pröprio funil de separação com duas lavagens de $300 \mathrm{ml}$ de ägua destslada, saturada de $\mathrm{Na}_{2} \mathrm{SO}_{4}$, desprezando-se as äguas de lava gens.

A quantidade remanescente que continha o pesticida foi concentrada para 1 mI em um concentrador "Kuderna Danish". Nessa quantidade ( $1 \mathrm{ml})$ foi feita uma clarificação final ou "clean-up" pela sua passagem através de uma coluna cro metogräflca conterdo florisil desativado com 58 de ägua destila da.

Eluiu-se com uma mistura de ëter etilico em éter de petróleo nas proporções de 6:94, 15:85 e 50:50. Concentrou-se novamente e injetou-se no cromatógrafo. As quantidacies injeta das variaram de 2 a 5 pl.

Todos os solventes empregados durante as análises re siduais foram puros e por vezes destilados de modo a torná-los pröprios para as anälises cromatográficas em fase gasosa. Fo ram testados no cromatógrafo de gās para evitar a justaposição de picos indesejäveis nos cromatogramas obtidos das anostras a nalisadas. 
Utilizou-se para as análises um cromatögrafo de mar ca Beckman, Modelo GC - 4 equipado com detector de captura de elétrons, com fonte de tritiom e com a temperatura da coluna de vidro a $178 \mathrm{C}$, contendo $10 \%$ de DC - 200 em Chromosorb - W. A velocidade do papel foi de $0,2 \mathrm{in} / \mathrm{min}$. ou $0,508 \mathrm{~cm} / \mathrm{min}$. Em alguns casos a velocidade do papel foi aumentada para melhor observação do pico e medidas da base e da altura dos cromato gramas. A coluna foi mantida a 1908 C durante a náaise e o gás de arraste foi o Nitrogênio com vazão de $100 \mathrm{ml} / \mathrm{min}$.

para cada uma das análises efetuadas, foi feito um branco ou "blanc".

Para efeito de cálculos,os padrões usados na croma tografia de fase gasosa tiveram as seguintes concentrações:

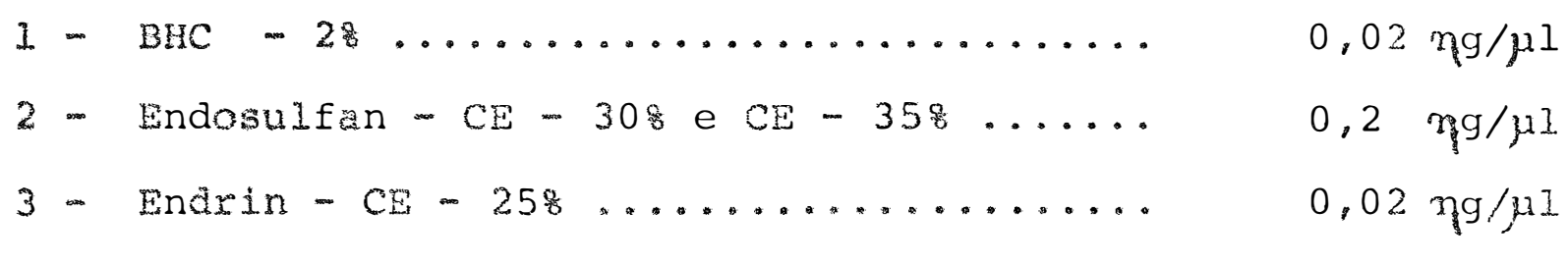

- Amostras com BHC:

A concentração final das amostras que foram injeta das no cromatógrafo foram de $0,04 \mathrm{~g} / \mathrm{ml}$ para os extratos obti dos das amostras da casca e de $0,2 \mathrm{~g} / \mathrm{ml}$ para os extratos oriun dos das amostras da polpa. Foram injetadas quantidades variä veis de 2 a 5 ul dos extratos no cromatógrafo.

- Amostras com Endosulfan:

A concentração final das amostras da polpa e casca 
dos frtuos que recoberam tratamentos em Endosulfan fol de 0,2 $\mathrm{g} / \mathrm{ml}$. As quantidades injetadas no cromstögrafo foram de 2 a 5 pl.

- Amostras com Endosulfan 30\% + Parathion metilico 10\% ( Endo metil - $\mathrm{CE}-40$ 号):

Nesta mistura de clorado + fosforado a concentração final das amostras injetadas no cromatōgrafo foi de $0,2 \mathrm{~g} / \mathrm{ml}$ tanto para as amostras da polpa quanto para as da casca. Tam be̊m foram injetados no cromatógrafo os volumes de 2 a $5 \mu l$.

- Amostra com Endrin - 258 + Paration metilico - 108 (Rhodiaendrin - CE - 358):

Do mesmo modo que no Endometil, esta ê uma mistura de clorado + fosforado. A concentração final que injetou- se no cromatógrafo foi de $2 \mathrm{~g} / \mathrm{ml}$ para os extratos oriundos de $\underline{a}$ mostras da polpa e da casca; igualmente, as quantidades inje tadas variaram de 2 a 5 pl.

Foram feitas 3 anālises para cada um dos inseticidas em cada intervalo considerado (14, 21 e 28 dias) tanto para as amostras polpas quanto para as amostras da casca.

Com microseringas injetou-se no cromatógrafo a gas aliquotas dos extratos de concentrações conhecidas. Calculou -se as quantidades de resíduos presentes nos extratos através de comparações com soluções que continham quantidades conhecidas do inseticidas e pela utilização da fórmula dada a seguir. 
4.4 - CALCULO DA QUANTIDADE DE RESIDUOS

Para os cälculos das quantidades dos residuos em ppm, empregou-se a fórmula abaixo:

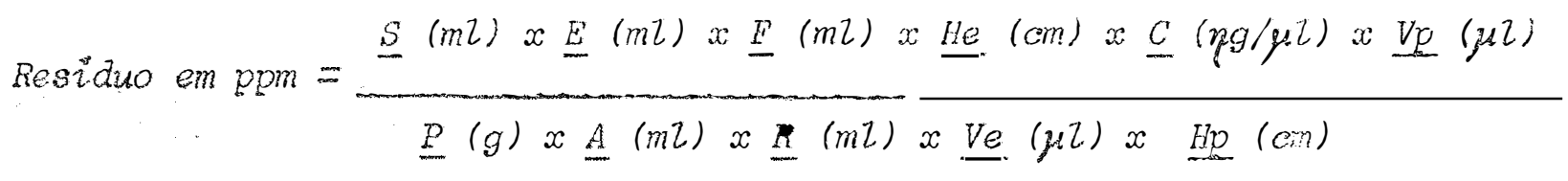

\section{Onde:}

$S=$ Volume da solução de extração (ml);

$E$ = Volume de éter de petróleo adicionado ao funil de separa ção (m1);

$F^{\prime}=$ Volume final do extrato (ml);

He = Altura do pico do extrato no cromatograma $(\mathrm{cm})$;

$C=$ Concentração da solução padrão do inseticida (ng/pl);

$V p=$ Volume da solução padrão injetada no cromatógrafo ( $\mu 1)$ :

$\mathrm{P}$ = Peso da amostra do material a analisar (polpa ou casca) (g):

$A=$ Volume da alíquota do extrato (ml);

$R=$ Volume de èter de petróleo recuperado no funil de separa ção (mI):

Ve $=$ Volume do extrato injetado no cromatógrafo $(\mu 1) ; e$

$\mathrm{Hp}=$ Altura do pico do padrão no cromatógrafo $(\mathrm{cm})$. 
5 RESULTADOS

Os resultados de residuos para todos os inseticidas foram expressos em (ppm) parte por milhão ou m de inseticida por $\mathrm{kg}$ de amostra.

5.2 - AMOSTRAS COM BHC - $2 \%$

Foi considerada a soma dos isômeros alfa ( $\mathbb{R}$ ), beta $(\beta)$, gama $(\gamma)$ e delta $(\Delta)$ contidos neste inseticida. As quantidades detectadas em ppm na polpa e na casca estão inse seridas nos Quadros 3 e 4 para os três experimentos.

Os resultados mostrados no Quadro 4 , revelam que os residuos do BHC persistiram nos frutos em grandes quantidades na casca: $(2,88 \mathrm{ppm} ; 1,75 \mathrm{ppm}$ e 2,13 ppm respectivamente pat ra os experimentos de 14 em 14, 21 em 21 e 28 em 28 dias) e 0,04 ppm:0,05 ppm e 0,06 ppm na polpa de abacaxis deste mesmo experimento. 
Este fato revela que para o consumo dos frutos devese observar rigorosamente o não aproveitamento da casca ou se ja a camada externa com profundidade até 1,5 a $2,0 \mathrm{~cm}$ pois ē nesta região onde os resíduos se apresentaram com teores eleva dos para O BHC.

O BHC foi também identificado através de cromatogra ma da casca dos abacaxis testemunha, porém não foi levado em consideração pois o foram em quantidades muito pequenas ou se jam (ppt) partes por trilhão. Acredita-se que este evento tenha sido produto de derivas, residuos deste inseticicia no so lo onde se efetuou os experimentos ou ainda contaminaçöes no laboratório.

5.2 - AMOSTRAS COM ENDOSULFAN - CE - 35\% (Thioddr)

O padrão do Endosulfan respondeu com dois picos no cromatograma e isto foi motivado pela presença dos dois isôme ros em que se decompõe o Endosulfan. Isômero I ou alfa $(\alpha)$ Endosulfan e Isomero I ou beta $(\beta)$ Endosulfan.

Os cálculos deste inseticida foram efetuados levando se em conta o somatörio dos dois picos. As quantidades de tectadas foram: $0,18 \mathrm{ppm} ; 0,16 \mathrm{ppm}$ e $0,09 \mathrm{ppm}$ respectiva mente nos experimentos de $14 \mathrm{em} 14,21$ em 21 e 28 em 28 dias. Na polpa detectou-se quantidades muito pequenas, na ordem de (ppt) partes por trilhão. 


$$
\begin{array}{r}
5.3-\quad \text { AMOSTRAS COM ENDOSULFAN - CE - 30\%+ PARATHION } \\
\text { METLISICO - CE - 20\% (ENDOMETIL - CE - 10\%) }
\end{array}
$$

Nesta mistura, detectou-se teores de Endosulfan da ordem de : 0,1l ppm; 0,13 ppm e 0,09 ppm na casca dos fru tos nos experjmentos de 14 em 14,21 em 21 e 28 em 28 dias res pectivamente. Na polpa, encontrou-se pequenas quantidades co mo no item 5.2 .

\section{4 - AMOSTRAS COM ENDRIN - CE - 25\% + PARATHION METILICO - $C E-20 \%$ (RHODIAENDRID - CE-35\%)}

o Endrin foi detectado como residuo persistente nas quantidades de $0,08 \mathrm{ppm} ; 0,03 \mathrm{ppm}$ e $0,03 \mathrm{pp}$ respectivamente para os experimentos de 14 em 14,21 em 21 e 28 em 28 dias pá ra as mostras da casca ; enquanto traços (ppt) foram encon trados nas amostras da polpa, Quadros 3 e 4 . 
6 - CONCLUSOES

Dentro das condições em que foram realizados os três experimentos pode-se concluir o seguinte:

a - Apenas os inseticidas BHC , Endrin e Endosulfan apresen taram residuos persistentes nos abacaxis.

b - Amostras de frutos tratados com BHC apresentaram teores re siduais de 2,88 ppm; 1,75 ppm e 2,13. ppm na casca e de $0,04 \mathrm{ppm} ; 0,05 \mathrm{ppm}$ e $0,06 \mathrm{ppm}$ na polpa, respectivamente para aplicações de 14 em 14,21 em 21 e 28 em 28 dias,res pectivamente.

c - O nivel de resíduos na casca dos frutos tratados com Endo sulfan revelaram que as quantidades persistentes foram: $0,18 \mathrm{ppm} ; 0,16 \mathrm{ppm}$ e 0,09 ppm nas aplicações respectivas de 14 em 14, 21 em 21 e 28 em 28 dias.

d - Fica nos frutos tratados com (Endometil - CE -408) Endosul fan - CE - 30\% + Parathion metiliCo - CE - 10\%, analisou-se 
para o Endosulfan o qual mostrou-se resíduo persistente nas quantidades de $0,11 \mathrm{ppm} ; 0,13 \mathrm{ppm}$ e 0,09 ppm nas amostras da casca aos intervalos de aplicação de 14 em $14 ; 21$ em 21 e $28 \mathrm{em} 28$ dias respectivamente. Na polpa partes por tri Ihão (ppt) foram detectadas.

e - Em amostras de frutos que receberam (Rhodiaendrin-CE-35\%) En drim - CE - 258 + Parathion metílico - CE - 10\% a casca a presentou residuos de Endrin da ordem de 0,08 ppm;0,03 ppm e 0.03 ppm para os três intervalos 14, 21, 28 dias respecti vamente. Na polpa apenas traços (ppt) foram observados.

f - Os resultados conseguidos mostram que o BHC foi o que per sistiu em guantidades mais elevadas, seguidos pelo Endosulfar e o Endrin, na casca dos frutos. Entretanto, como o abacaxi não consta na ỉsta dos frutícolas que têm os lizmi tes de tolerância de resíduos já fixados; por ł̇sso, as quan tidades residuais aqui apresentadas não podem ser considera das alarmantes ou despreziveis para este fruto, mas, ao ve rificar-se os limites de tolerancias jä estabelecidos para ou tros frutos poder-se-á notar a periculosidade do consumo da casca d•s abacaxis nas indüstrias de sucos. 
$?$ - SUMARY

This research deals with chlorinated inseticides resi dues BHC - 2\%, Endosulphan - EC - 35\%, Endosulphan -EC- 30\% + Pa rathion methyl $10 \%$ and Endrin- EC- 25\% + Parathion methyl 10\% in rind and pulp of pineapple fruits Ananas comosus (L.) Merril cv. Smooth cayenne.

Three experiments were done at intervals of 14,21 , and 28 days. Each experiment consisted of 3 blocks of lo plots ( 4 treated and 1 check) of 36 plants being the 10 central ones the useful plot.

Fruiting was induced by using Calcium Carbuett ( $2 \mathrm{~g} /$ plant) in April 10, 1972. The first insecticide application was made in July 26, 1972 and the last was made in october 18, 1972 ; the fruits were harvested in December 5, 1972.

The analysis were done according to the methodology des cribed in Analytical Method J.A.O.A.C. (1970) for residues of chlorinated. 
From each sample of 3 fruits, $50 \mathrm{~g}$ of pulp, or rind, were mixed in a blendex with $100 \mathrm{ml}$ of acetonitrile and $5 \mathrm{~g}$ of celite. The solution was filtered by suction and the volu me completed to $1,000 \mathrm{ml}$. The pesticide was extracted with $100 \mathrm{ml}$ of petroleum ether, washed, purified and concentrated to $1 \mathrm{ml}$. Clarification was made in a chromatograf column con taining disativated florisil 5응 with wather, the material vas eluted in ethilic ether and petroleum ether concentrated and injected in the chromatograph, column temperature $1798 \mathrm{C}$ con taining 108 of DC - 200 in chromosorb - $W$ and paper velocity $0.508 \mathrm{~cm} / \mathrm{min}$.

The standard employed had concentrations of $.02 \mathrm{ng} / \mathrm{ul}$ for BHC and Endxin, and $.2 \mathrm{ng} / \mathrm{l}$ l for the Endosulphan.

The following results were obtained:

HC residues: $1.75-2.88 \mathrm{ppm}$ (rind) and .05-.07 ppm (pulp); Endrin residues (Rhodiaendrin): .08 ppm, (rind) and traces (ppt) in the (pulp); Endosulfan residues ( Endorne til), in the rind: $.09-.11 \mathrm{ppm}$, and traces (ppt) in pulp; Endosulfan residues (Thiodan), in the rind: .09 - .18 ppm, in the pulp was detected traces (ppt). 
ALMEIDA, W. F. e B. SVETLICIC, 1972. Aspectos de saüde püblica referentes ao uso de pesticidas no Brasil. O Biolögico, São Paulo: 38(4): 99-104.

ALMEIDA, W. F., 1973. Tolexância de residuos de pesticidas a nivel internacional. O Biológico, São Paulo, 39(7): 188-189.

ALMEIDA, W. F., 1974. Acümulo de inseticidas no homem e sua significação epidemiológica. O Biológico, São paulo, 40 (6) : $\quad 171-183$.

ALMEIDA, W. F. A A.P. PEREIRA 1973. Problemas de saüde ocupa pacional na agricultura. O Biológico, São Paulo, 39(9): $233-239$.

ANALYTICAL METHODS OF ANALYSIS in "JOUNAL OF ASSOCIATION OF OFFICIAI ANALXTICAI CHEMISTS, 1970. General Methods EOr Chlorinated pesticides. $15 \mathrm{ed}$. , washington, DC, p. 475.

BANCO DO BRASIL S. A. 1975. As frutas de exportação. CACEX Informativo Semanal, Rio de Janeiro, 10(451): 1-15. 
BARON, Le Allen, 1971. Pesticides use or non use economics as a basis for policy decisions. Utah Science, Logan, $\underline{32}$ (2): $69-72$.

BATISTA, G. C., 1974. Fundamentos de toxtcologia das inseti cidas. Apostila do Curso de Pós-Graduação em Entomologia. ESALQ/USP, Piracicaba, $257 \mathrm{p}$.

Rasil. Ministério da Saúde. Comissão Nacional de Normas e Padröes para Alimentos, 1972. Residuos de Pesticidas em Alimentos. Brasilia, 47p.

BRAsIL. Ministerio do Interior, 1973. Abacaxi Nordestino. pesquisa de Mercado na Europa e Estados unidos. Fortaleza Banco do Nordeste do Brasil, $330 \mathrm{p}$.

BRASIL. Ministério da Saüde. Comissão Nacional de Nomas e Padrões para Alimentos, 1974. Resolução no 12. Diärio Oficial da União, Rio de Janeiro, 17 de julho de 1974. seçă• I, pt. 1, p. 8060-8061.

BRASIL. Ministério do Intertor, 1976. Abacaxi Nordestino. Pesquisa de Mercado na Europa e Estados unidos. Fortaleza, Bance do Nordeste do Brasil, $230 \mathrm{p}$.

-RASIL. Ministërio da Agricultura. Departamento Nacional da produção Vegetal. Divisão de Defesa Sanitária Vegetal, 1978. Catálogo dos Defensivos Agrícolas, Brasilia, $427 \mathrm{p}$.

BRASIL. Ministërio da Agricultura. Departamento Nacional da Produção Vegetal. Divisão de Defesa Sanitäria Vegetal, 1978a. Prevencão de Acidentes no uso de Defensivos. Brą silia, $74 \mathrm{p}$.

BREITNER, H. J. O., 1972. Pesticide Residue Analysis. CIPA Conference, Brasilia, FAO/WHO, 14p. 
CARson, R., 1962. Primavera silonciosa. São paulo, kd. Me Ihoramentos, $3.5 \mathrm{p}$.

CATOLA, R., 1969. Introdução à Cromatografia em Fase Gasosa. São paulo, Associação Brasileira de Química, 264 p.

DE WITT, J.B., 2955. Effects of chlorinated hidrocarbons insecticides upon quail and pheasants. J.Agric. Food Chem. Washington, 3: $672 \mathrm{p}$.

DIMICK, K. P. e H. HARTMANN, 1963. Gas chromatagraphy for the analysis of pesticides using Aerograph electron capture de tectos. Residue Reviews, Berlin, 4: 15-172.

EDWARDS, C. A., 1970. persistent pesticides in the environ ment. In: Critical Reviews in Environmental Control. Cleveland, Chemical Rubber Co., v. 1, p. 1-67.

ETTRE, L. S. E W. H. MC FADDEN, 1969. Ancillaxy Techningues of Gas Chromatography. New York, Interscience Publ., 395 po

Fno who, 1967. Residuos de plaguicidas en los Alimentos, Ro ma, Informes Tëcnicos no $370,18 \mathrm{p}$.

FAO e WHO, 1968. Residuos de Plaguicidas. Roma, Serie de In formes Tëcnicos $138391,36 \mathrm{p}$.

FAO $\mathrm{WHO}$, 1969. Pesticides Residues in Food. Røa, Techni cal sëries, n8 $417.40 \mathrm{p}$.

FAO C OMS, 1970. Norma Internacional Recomendada para la Pi ña en Conserva, Comission del codex Alimentarius. 24 p.

FAO e WHO, 1970a. Informe del Simposio de la FAO sobre la Re sistencia de las Plaqas Agricolas e los Insecticidas. Roma, Sërie de Informes Técnicos, $22 \mathrm{p}$.

EAO e WHO, 1970b. Resistencia de las Plagas a los Plaguicidas on la Agricultura, su Importancia, Determinacion y medidas pa ra combatirla. Roma, Sërie de Informes récnicos, $37 \mathrm{p}$. 
Fro o WHo, 1971. Evaluations of some pesticides in food. Roma, Technical Series. $571 \mathrm{p}$.

FAO e WHO, 1971a. Residuos de Plaguicialas en los Alimentos. Roma, Sexte de Informostécntcos, ng 84, 48 p.

PAO e WHO, 1917b. Residues de Plaguidias en los Alimentos. Roma, Série de Informes Técnicos, no 458, 50 .

FAO e WHO, 1971c. Manual sobre el Empleo de las Especificaciones de 3 a FNO para productos Destinados a la Proteccion de las Plantas. Roma, Cadernos de Fomento Agropecuario. no $93,49 p$.

FAO $e$ WHO, 1976. Wimites Mäximos Internacionales Recomenä dos para los Residuos de plaquicidas. (5 ${ }^{a}$. séxie). Roma, $18 \mathrm{p}$.

FNo $e$ WHO, 2977. Residuos de Plaguicidas en los Alimentos: Infome de la Reunion conjunta de 1975 del Grupo de Traba jo de erpextos de la PAO sobre residuos de plaguicidas y del comitè de expextos de la oms en residuos de plaguici dias. Roma, Informe Agropecuärio no 1,49 .

FEHN, L. M. E A. M. BERTELS, 1971. Testes Toxicológicos com Inseticidas. pelotas, IPEAs, (Cixcular, no 47). 16 p.

FLEMING, W. E. e W. W. MAINES, 1953. Persistence of DDT in soils of area infested by japanese beetle. J. Econ. Ento mol., college park, $46(3): 445-449$.

FORMAN, S. E. ; A.J. DUBERTAKI; M. V. COHEN E R. A. OLOFSON, 1965. The configurations and confirmations of the two iso meric Thiodans. J. Oxg. Chem., Washington, 30 (1): 1691975 .

FRHKSE, H., 1964. Special features in analysis of pesti cides residues; residues analysis and food control. Resi due Reviews, New York, 5(1): $1-20$. 
GAETA, R., 1974. Riscos o controle de individuos expostos à ação dos pesticidas. O Biolögico, São Paulo, 40 (9): 271277.

GALLO, D. ; O. NAKANO; S. SILVETRA NETO; R. P. L. CARVALHO; G. C. BATISTA; E. BERTI FILHO; R. A. ZUCCHI E S. B. ALVES, 1978. Manual de Entomologta Agricola. São Paulo, Ed. Agronômica ceres, $531 \mathrm{p}$.

GIACOMELLI, E.S., 1973. Estudos sobre o comportamento do a bacaxizeiro Ananas comosus (L.) Merril, Cultivar Cayenne na região de Bebedouro, Estado de São Paulo. (Tese de dou toramento). Piracicaba, ESALQ/USP, $37 \mathrm{p}$.

GIACOMELII, E. J., 1977. Relatóxío de Curso sobre Rabacaxi Cultura Mundial e Contemporânea a Nîlel de pós-Graduação. Fortaleza, Banco do Nordeste do Brasil, 29 p.

GIACOMELLI, E.J., 1977a. Relatörio de viagem ao mundo aba caxicola. Fortaleza, Banco de Nordeste do Brasil, 49 p.

GIACOMELII, I. J., 1978. Relatörio geral das atividades de 1976 e 1977 do acordo com o Bance do Nordeste do Brasil e Instituto Agronômico do Estado de São Paulo, Fortalezà. $28 p$.

GIANNOTTI, O., 1973. O uso de defensivos agrícolas e o pro blema de residuos. O Biológico. São Paulo, 39(8): 210211.

GIANNOTTI, O.; A. ORLANDO; D. PUZZI; R. D. CAVALCANTE E E. J. R. MELLo, 1972. Noçöes básicas sobre praguicidas: Ge neralidades e recomendações de uso na agricultura do Esta do de São paulo. O Biológico, São Paulo, 38(8-9): 223339 . 
GIANNOTTI, O. ; D. MELIL e W. F. ALMEIDA, 1974. Polujęão de

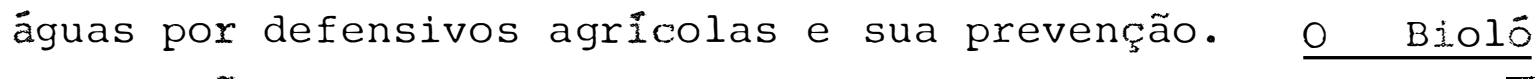
gico, São paulo, 40 (4): 125-126.

GINGBURG, J.M. e J. P. REED, 1954. A Survey of DDT acumulation in soils in relation to different crops. J.Econ. En tomol., College Park, 47(3): 467-474.

GRAHAM, J.E., 1971. Some benefits of pesticides in public health. Utah Science, Logan, 32(2): 50-52.

GUDZINOWICZ, B. J., 1967. Gas Chromatographic Analysis of Drugs and Pesticides. New York, Marcel Deker 605 p.

GUYER, G. E. 1969. What is happening to applied entomology? Bul1. Entomol. Soc. Am., College Park, 15 (2): 83-84.

HUNT, E. G. , 1966. Biological magnification of pesticides. In: National Academy of Sciences. National Research Coun c1l. Scientific Aspects of Pest Control. Washington, NAS/ NRC, P. 251-262.

JAMES, A. I. e A. J. P. MARIN, 1952. Gas-liquid partiti on chromatography. A technique of the analysis of volati les menerals. Analist, London, 77: 915-932.

JOHNS, T. e C. H. BLAITWHAITE, 1964. Selective detection and identification of pesticides residuos. Residues Reviews. New York, 5: 45-56.

JORNAL DO BRASIL, 1973. Vegetais e Erutas do Rio de Janeiro receben inseticidas em doses exageradas. Jornal do Brasil Rio de Janeiro, 16 de junho de 1973. C. 1, p. 15.

KENAGA, E. E. e W. E. ALLISON, 1969. Commercial and experimental organic insecticides. Bull. Entomol. Soc. Am. College Park, 15 (2): 85-160. 
KENAGA, E. E. e C. S. END, 1974. Comercial and experimental organic inseticides. Special publication of Entomol. Soc. Am., Michigan, $77 \mathrm{p}$.

LARA, W. H., 1971. Determinação de residuos de pesticidas or gano-clorados em alimentos; definições e considerações ge rais. Rev. Inst. Adolfo Lutz, São Paulo, 31 : 125-132.

LICHTENSTEIN, E.P., 1958. DDT accumulation in mi- western orchard and crop soils treated since 1945. J. Econ. Ento mol., College Park, 50 (4): 545-547.

LINDGREN; W. B. e I.E. VINCENT, 1968. pesticide residues in post harvest frults. Residue Reviews, New York, 28 : 1-121.

MIER-BODE, H. 1968. Properties, effects, residues and ana lytics of the insecticides Endosulfan. Restdue Reviews, New York, 22: 1-44.

MC NAIR, H. M. e E. J. BONEIII, 1969. Besic Gas Chromatography. S. 1. Varian Aerograph, 306 p.

MARTIN, H. , 1968. Pesticide Manual; basic informations on the chemical used as active components of pesticides. Lon don, British Crop Protection Council, $464 \mathrm{p}$.

METCALF, C. I. e W. P. FLINT, 1972. Insectos destructivos e insectos utiles: sus costumbres e su control. Mëxico, Ed. Continental, $1.208 \mathrm{p}$.

NEKANO, O. : SILVEIRA NETO; G. C. BATISTA ; M. YOKOYAMA ; N. DEGRSPARI e L.C. MARCHINI, 1977. Manual de Inseticidas. São Paulo, Ed. Agronōmica ceres, $272 \mathrm{p}$.

NEUHOLD, J. M. 1971. Pesticides and ecology. Utah Science. Logan, $32(2): 39-41$. 
O' BRIEN, R. D., 1967. Insecticldes; Action and metabolism. New York, Academic Press, $332 \mathrm{p}$.

OLIVEIRA, J.V. e G. C. BATISTA; 1976. Avaliação quantita tiva de residuos de inseticidas organo-fosforados em couve Brasica ozeracea var. acephata I. pela bioanälise com lax vas de Aedes aegypti (I., 1762) (Dip. Culicidae). Ecossistema, Espirito Santo do Pinhal, I(1): 45-53.

OLSEN, J. I. , 1971. Pesticides in public health. Utah Scien ce, Iogan, $32(2): 45-46$.

PRIMBLAD, I. 1971. Pesticides and populations. Utah Scien ce, Logan, $32(2): 74$.

PIEDADE, J. R. , 1975. Considexações sobre anälises e decom posifão dos defensivos agrícolas. o Biológico, são Pau $10,41(6): \quad 155-158$.

PIGATrI, P. 1973. Métodos biológicos para determinação de residuos de inseticidas. O Biolögico, são paulo, $39(7)$ : $189-191$.

PX, C. e M. A. TISSEAU, 1965. I'Ananas, Paxis, MoisonNeuve \& Larose. $298 \mathrm{p}$.

RIBAS, C. 1976. Estudo da persistência de resỉduos de Iindane e Endosulfan através de cromatografia à gâs, em grãos de café. Piracicaba, ESALQ/USP, 95 p. (Dissertação de Mestrado).

ROBERTS, R. S., 1971. A brief history of pesticides uses. Utah Science, Logan, $32(2): 42-44$.

ROSEN, A. A. E F. M. MIDDLETON, 1959. Chlorinated insecticides in surface Whater. Anal. Chem, Easton, Pa, 31: $1729-1732$. 
RUEGG, E. F. , 1975. Téndeas de radiotsótopos para cutadar os efeitos residuais de pesticidas em plantas alimenticias.

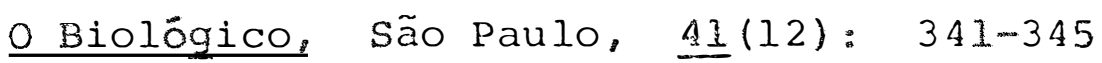

SÃO PAULO - Prognōstico 74/75. 1975. Secretaria da Agricul tura, Instituto de Economia Agrícola, $226 \mathrm{p}$.

SHARMA, R.P. , 1971. Mechanjsm of pesticide toxicity. Utah Science, Logan, $32(2): 57-58$.

SCHUPP III, O.E. , 1968. Gas Chromatography. In: PERRY , E. S. e A. NEISSBERGER, ed. Techinique of Organic Che mistry. New York, Intercience, Publishers, V. 13. 473

SIMÃO, S. "1971. Abacaxizeiro. In: SIMÃO, S. Manual de Eruticultura, São Paulo, Editora Agronônica Ceres, 530 $p$.

SIMPOSI sobre "ResIduos de inseticiaas em produtos alimenticios. 1973. O Biológico, são paulo, 39(8): 208-209.

STREET, J. C., 1971. Regulation of pesticides. Utah Scien ce, Logan, $32(2): 62-64$.

THOMPSON, R. P. H. ; C.W. T. PILCHER ; J. ROBINSON ; G. M. STATHERS; A. E. M. MC LEAN e R. WILLIAMS, 1969. Treat ment on conjugated jaundice with dicoplane. Lancet. Lon don, $2(4 / 6): 7.610$.

TRANCHANT, J. , 1969. Practical Manual of Gas Chromatography. Amsterdan, Elsevier, $387 \mathrm{p}$.

TUCKER, R. K., 1971. Chlorinated hydrocarbons cause thin egg shells but so may other pollutants. Utah Science, Lo gan, $32(2): 4749$. 
50.

$9-\quad A P E N D T C E$ 
$\frac{\pi}{2}$

F

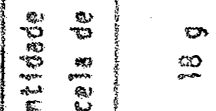

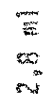

ב."

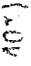

$m$

邑

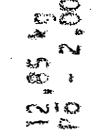

s.

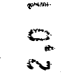

$\because$

$\kappa$

$\operatorname{li}_{0}$

$\stackrel{5}{-}$

.

o

in

$-10 \mathrm{~N}$

$\rightarrow \infty \pi$

$+$

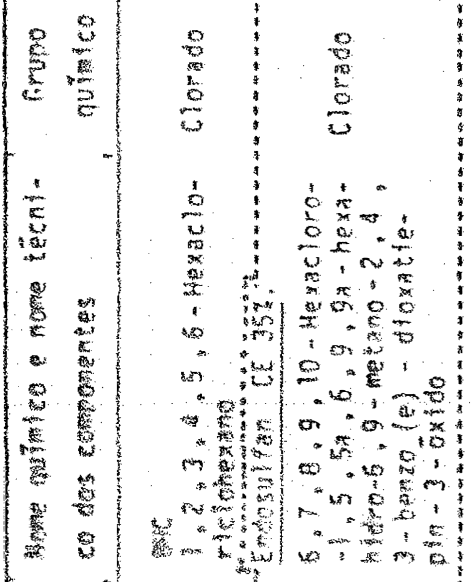

$\therefore+$

0
5
5
25
50
50

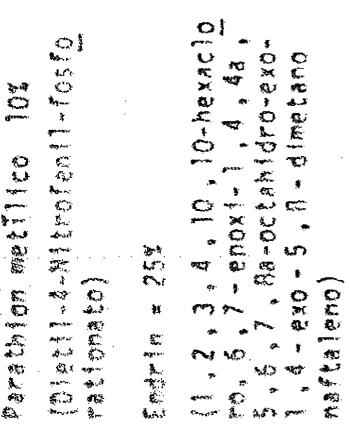

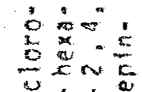

of

900

ton.

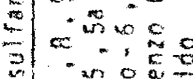

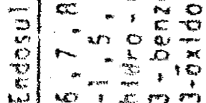
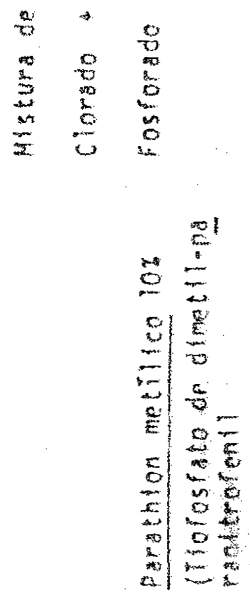

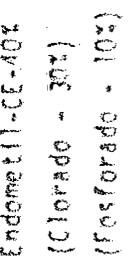


52.

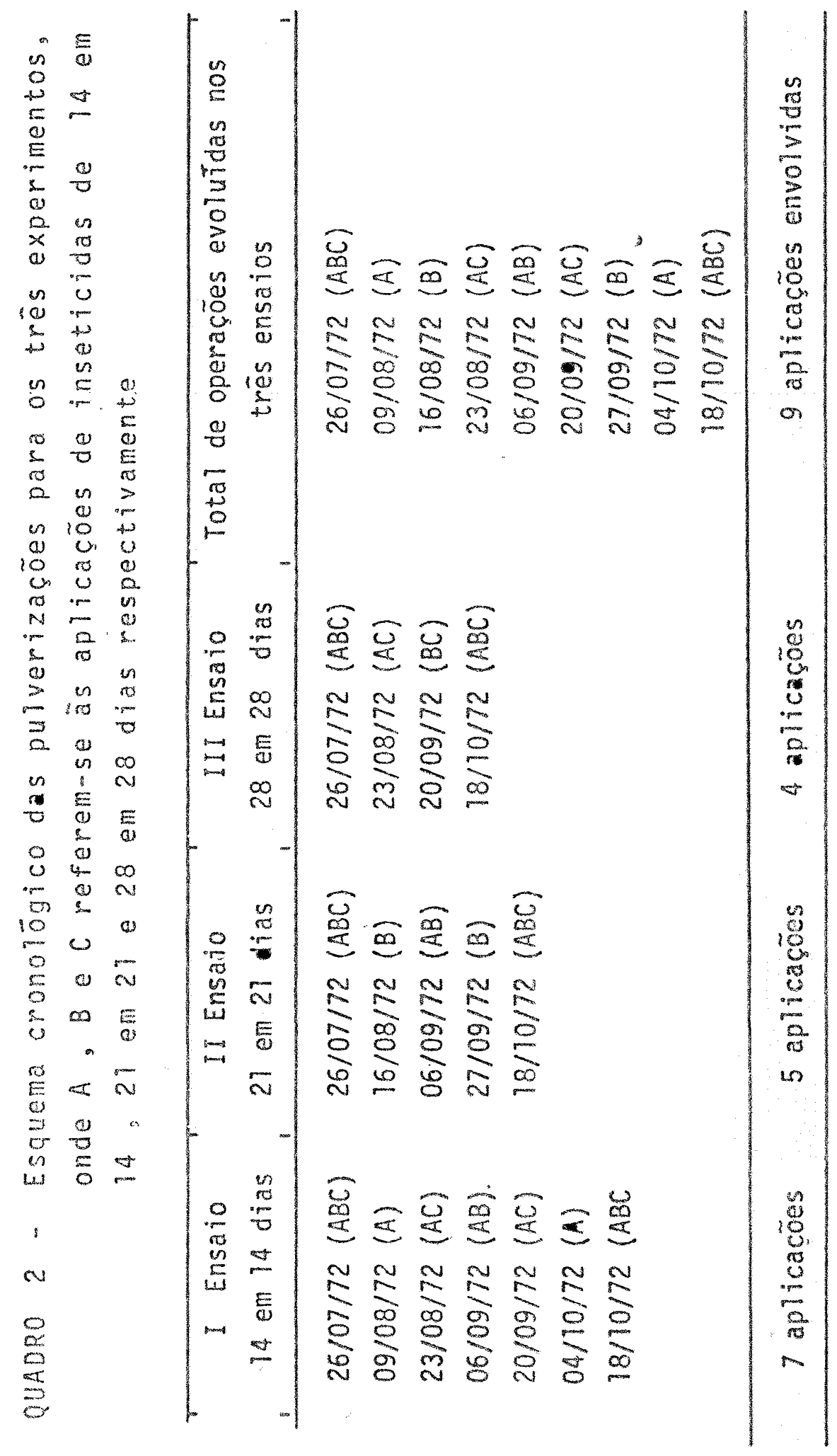




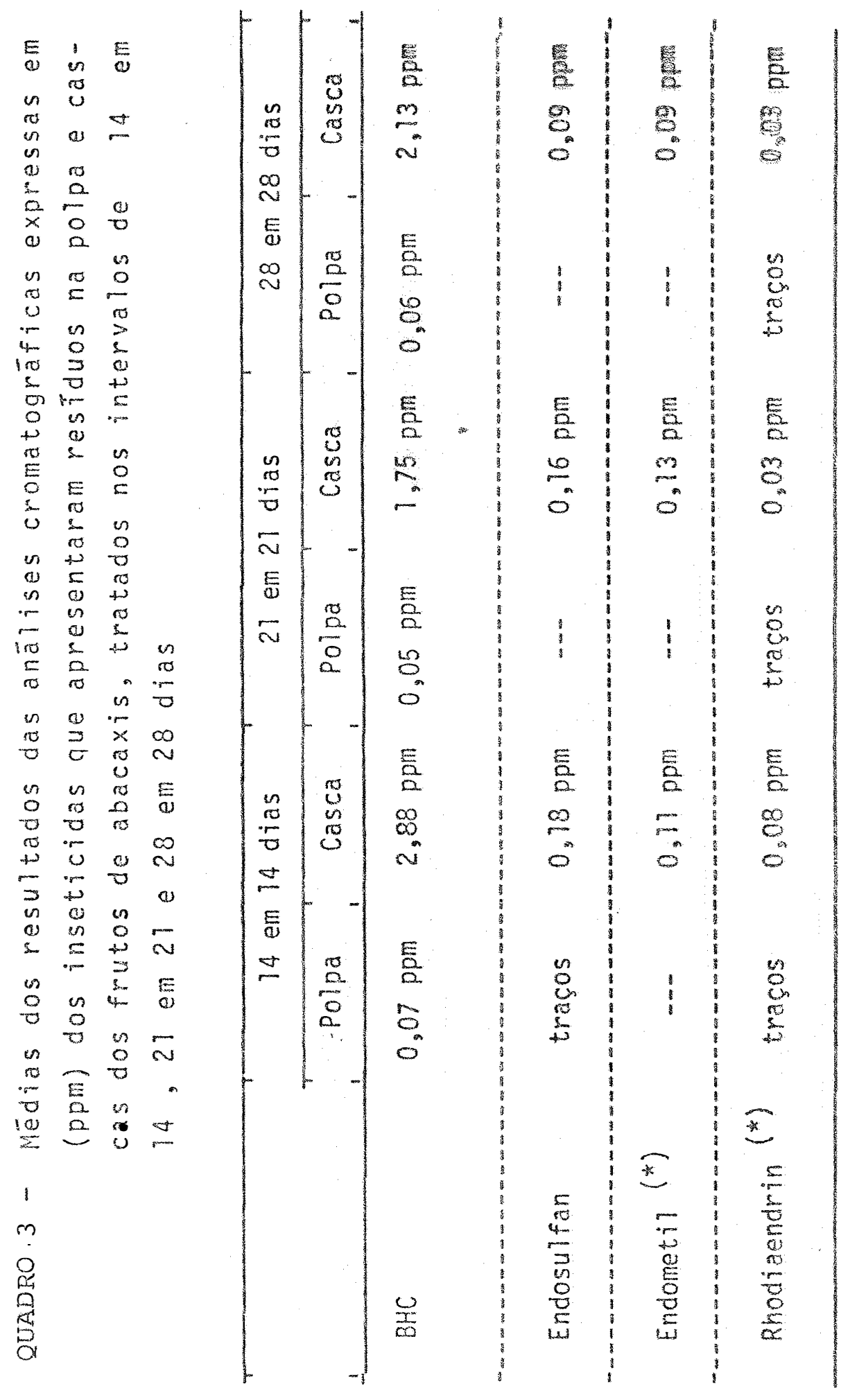




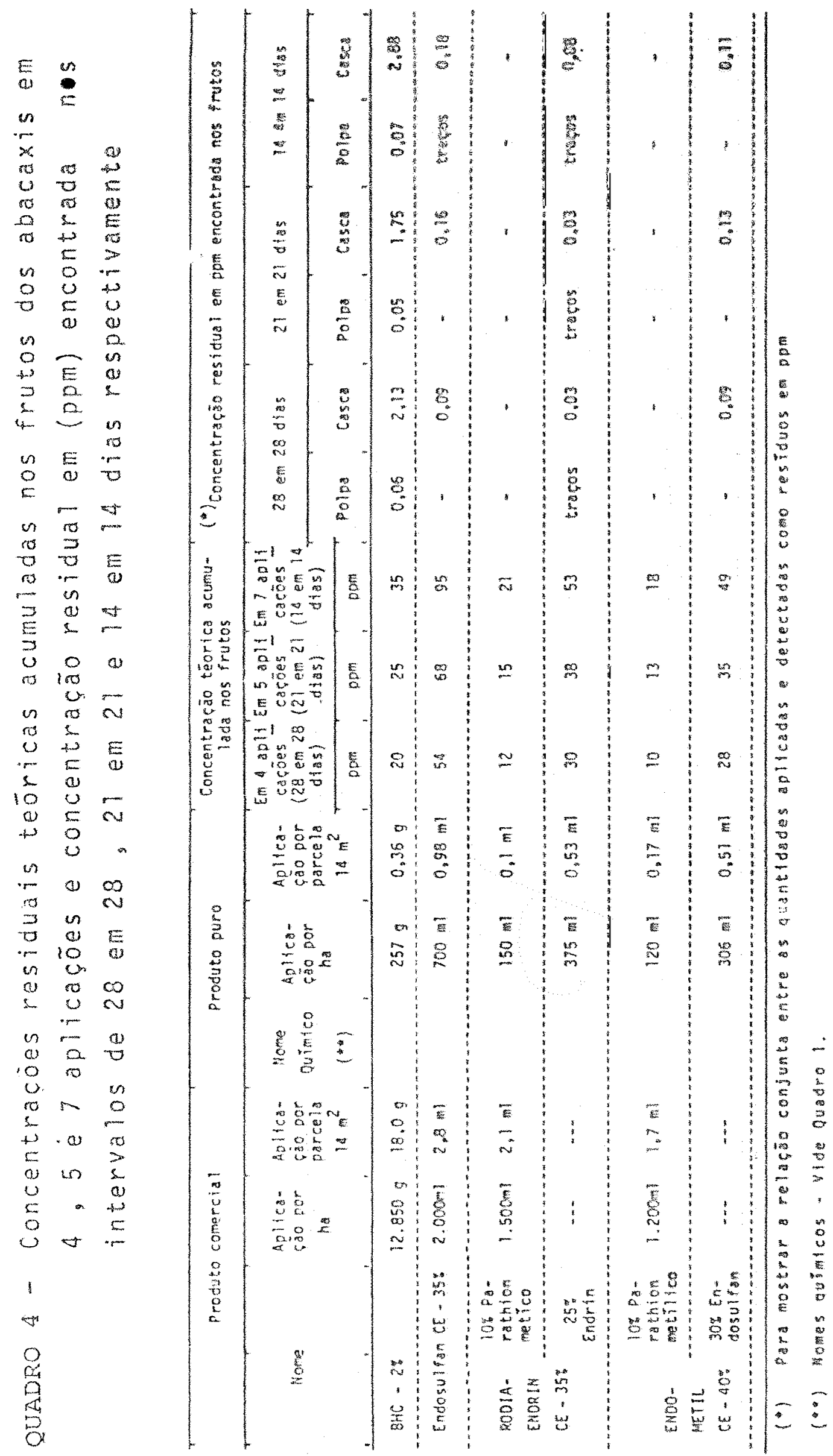

